\title{
The applied talent cultivation of civil engineering surveying teaching practice exploration
}

\author{
Xinhua ZHANG ${ }^{1, a}$ \\ ${ }^{1}$ College of Civil Engineering, Shanghai Normal University, Shanghai, 201418, China \\ aEmail: zhxh152@shnu.edu.cn, 13162557029@126.com
}

Keywords: Engineering survey; Practical teaching; Applied talents.

\begin{abstract}
The engineering survey curriculum positioning and requirements under the new situation, the emphasis on strengthening the practice teaching is to cultivate applied talents needs, improve the engineering survey course practice teaching plan, elaborated implement countermeasures practice teaching, from students comprehensive teaching effectiveness evaluation, reflecting the practice of teaching process and give full play the initiative and enthusiasm of students, help train talents of applied technology.
\end{abstract}

\section{Introduction}

Combining theory and practice of civil engineering surveying is a fairly close professional basic course, mainly includes the basic measurement, topographic survey and construction survey, setting up practice teaching links include theory teaching, the class recess and focused practice three phases, to cultivate undergraduates comprehensive grasp the elevation difference, the three basic parameters of Angle and distance measuring and mapping, map reading, with a figure, lofting of basic skills and practical ability, and the measuring of the capability of technical analysis and solve problems plays an extremely important role. Project implementation process, from of topographic map surveying and mapping of reconnaissance design phase, construction phase of the construction and completion of measurement and operation management phase of safety test and deformation observation, measurement technology, which has always so enhance the students engineering surveying practice teaching link, is advantageous to the students enter the ability to quickly adapt to work.

\section{Clear course orientation, focus on the ability}

Curriculum reform focuses on cultivating applied talents, which closely associated with engineering students in our school orientation, at present, the engineering measurement theory and experiment period ratio is about 2:1, concentrated practice 2 weeks, to construct the reasonable engineering surveying course system, and fully embodies the theory and practice in engineering education and the education idea. In recent years of professional planning and professional structural adjustment, engineering survey theory class period reduced 9 hours, but experiment practice link ratio increased.

In recent years, new equipment and new technology, new method of surveying and mapping to speed up the promotion use, according to the development of science and technology at the same time to satisfy the demand of the applied talents of engineering surveying course teaching reform put forward higher requirements. In determining the teaching content, therefore, guided by the traditional surveying and mapping theory, by means of modern surveying and mapping technology, meet the needs of the engineering survey technology, for the purpose of timely changes to the outline of the syllabus and experiment, practice, choice or recommend suitable for modern engineering needs of engineering surveying teaching material, experiment, practice instruction and resources.

Increase the practice of the practice teaching link, the measuring point to the project process training, survey, construction and construction will be enterprise demand for applied talents 
reasonable applied into the teaching process, usually with the aim to cultivate technology skilled talents, and adjust the engineering surveying course teaching content, teaching methods, to speed up the college students' ability training, shorten the gap between college students and professionals, able to quickly get started after obtain employment, between seamless docking, shorten the adaptation of students into the society.

The reasonable adjust the structure of the course content. Current curriculum has changed the past that kind of heavy, heavy theory, light practice mode, properly reduce the requirement of the basic theories, improve the requirements of the engineering survey in the practical engineering application, appropriate smaller parts, and adjusted in time according to the teaching hours and increase or decrease. On the whole content, do not need to emphasize the course of systemic and integrity.

Update content outline. Eliminate outdated measurement methods and means, timely added new equipment and new technology, new method of measuring technology, put forward reasonable requirements, promote the integration of teaching model, so that reasonable implementation in the teaching.

Between practice and focus on practice is indispensable to engineering surveying course two important link, to play the theory with practice, to consolidate and deepen the effect of classroom teaching, to cultivate the students' practical ability is very important. Before the revision of the experimental program mainly focus on the commonly used instruments and tools used, verification experiment is more, the revised outline of experimental measurement project as the theme of improving practice in engineering practice, cultivate students' comprehensive application ability and innovation ability. Revision before the internship program of topographic mapping part time is more, the graph and construction lofting content requirements is low, the information feedback from the students after graduation, students majoring in civil mainly focus on the construction survey, before teaching mode for students in the future work is very bad, the revised outline of internship, according to different professionals, of topographic map surveying and mapping, topographic map application and construction lofting content such as reasonable requirements are put forward.

Teaching materials directly influences the quality of quality, from the research collected forty engineering surveying teaching material, selected from a few this new excellent series of teaching materials for the use of teaching, to recommend to other students of the teaching reference books. We selected teaching material, supplemented by the use of advanced equipment, advanced technology, such as electronic level, RTK, computer mapping system and GPS precise leveling technology, the new technology such as high-speed railway construction survey, fully embodies the teaching material of high and new, essence, etc.

\section{To improve teaching efficiency}

The discretion of the instructor ability quality, directly affects the teaching quality. Teachers' teaching of engineering survey, in addition to have other teacher's professional quality, but also need more to improve their ability, not included in the latest modern surveying and mapping technology such as the teaching material, through the relevant data collected selectively into the classroom, enrich the teaching content. Particularly want to pay attention to their study, research and practice, and even to the construction site to direct measurement, continuously improve the level of theory and rich practical experience, so as to achieve a simple, vivid and according to the teaching effect.

Classroom teaching to do fewer but better, highlight key, difficult and doubtful point, make full use of the PPT, animations, models, methods such as physical, simplify complicated content, difficulty content popularization and abstract content specific, organize students to self-study, select the appropriate section on the formula derivation and complex mathematical operations, to speak your mind, let the students self-study after, and combining with the questions, the professional conduct classroom discussion, guide the students' thinking, active classroom atmosphere. Heuristic teaching, fundamentally change the situation of the students passively listening, cultivate the students' self-study ability, the ability to analyze and solve problems. Through a variety of means, 
high standard will be practical, skills training, complex structure of the instrument, and the content of the difficulty of the operation, the image intuitively reflected, facilitate students to understand and master, and get twice the result with half the effort.

Engineering measurement is a practical course, the stand or fall of measuring practice is directly related to the improvement of the student beginning ability. In order to achieve the desired effect, the establishment of a relatively stable experimental practice base, to develop the instrument management regulations, strictly abide by the experiment, practice guidance system, the requirement of the outline of the outline according to the experiment and practice, careful organization, reasonable arrangement of experiments and practice.

\section{The practical teaching plan and design}

In engineering surveying practice teaching is the advantage of a suitable venue and favorable conditions to design the practice teaching, teaching process and content will be in practice to implement the project. In the curriculum practice I designed three levels of practice: the first integrated teaching mode, the second recess to improve the practice, the third training practical exercises.

Technical understanding of measurement methods on students in class will not clear, the teacher speaks again well, not through the practice of exercise, and the students can't understanding measurement technology. Students seem to understand that in class, the operation principle of just picked up the instrument brain a blank. To realize the integration of theory and practice of curriculum teaching, and the technical equipment scene timely introduction to the theory and practice teaching, the timely introduction of field scene, shortened the distance between theory and practice teaching, eliminates the student space transformation and thought process, the students picked up quickly master the technical essentials and quickly achieve the teaching effect. Integrated teaching mode change teaching theory and practice of separation, technology and operation fragmented situation, after the module into the corresponding theory and practice training, students practical grasp of real-time theory and technology essentials, achieve targeted, carried out in a planned way measuring practice. Adopting this teaching model, which is beneficial to let the students know in what to do, how to do, so you can practice actively.

Change the traditional teaching management mode, the integration of teaching according to the requirement of the teaching content more transform teaching sites and teaching methods, this model and common patterns of teaching management in colleges and universities, I adopt the integration teaching mode in class this term in contradiction, the pattern needs in terms of teaching management, teaching management to the teaching reform policy to encourage and support, let the teacher does not have any concerns to the implementation of teaching reform.

As college students, can only operate the instrument is not enough. I am worked in a construction enterprise engineer for more than ten years, is to know what kind of person in construction enterprise is relatively easy to get started. Improve the practice link in the following steps:

First select the appropriate field on campus to ensure one of the key factors of construction engineering surveying practice teaching. Comprehensive factors related to the characteristics of the terrain, physiognomy in our school, a complex building and adjacent mall as the engineering measure to improve practice two campus practice teaching field, complex building when the building layout of settlement observation point is more specification, peripheral datum and 2, as long as a little repair ready-made site becomes deformation observation, in the complex boundary conditions of the big lawn due to consider factors such as drainage, plant landscape is beautiful, form the geographical environment of strewn at random discretion, for the engineering survey is a great site.

Complex building a total of 38 points, when leveling comprehensive improve practice, I adopted by leaps and bounds set point division method is assigned to each group, in the class for 2 class time, jump to assigned to each group of 8-10 points, for the position, let the students according to the actual putting decide to choose different ways of observation route and closed adhesion, set to 
determine the settlement observation point elevation, with a certain reference point $\mathrm{H}= \pm 0.000 \mathrm{~m}$, with the method of closing level line, observation height of each point. Set the measurement requirements: to use two meter high and double method of simultaneous determination; Observation line set, add the necessary turning point; Precision meet the engineering requirements. The request has the certain difficulty for beginners, this technology includes two kinds of the use of different level measurement method in practical engineering, have the effect of mutual check, is actually the embodiment of three fourth elevation control survey specification, before and after it comes to measuring the visibility is poor, poor range before and after the cumulative difference, red brown, red brown readings of the elevation difference control requirement of the poor, and need to control settlement of level error of each measuring point observation sequence. Observation of data processing are also used in the industry after the engineering requirements, one is the error of judgment, transfinite direct observation, a lot of team quickly carelessly done, the results calculated dumbfounded, serious error overrun; Secondly, the error is less than the allowed range, also need to undertake adjustment analysis (closure adjustment), the number of required to correct the sum and difference closure equal, symbols, on the other hand, per the measured elevation difference and the corresponding correction for the measurement section and elevation difference after being corrected.

Mall plot area of relatively large, in class time less affected by stream of people and vehicles, suitable for class time on basic measurements, such as the understanding of the level, theodolite, total station and basic operation; Closed route leveling; Angle and distance measurement, etc. The site is relatively open, wide vision, instructor at the scene for students to practice guidance and supervision and management are very convenient. And the site topography, bigger difference, the obvious features of topography, terrain change is bigger, features are more abundant at the same time, the main road, winding stone path, scattered trees, the grass vegetation, such as auxiliary facilities on campus, close to the project of the specific conditions of the line, is helpful to carry out digital mapping measuring project, construction lofting and so on. We use this site very good, first setting control points and site measurement, in order to make the arrangement of the point to use for a long time, in the corresponding position of training venues, set the spacing and tidy, reasonable distribution, mark clear, strong stability, a sufficient number of control points, is conducive to the position of the group practice bounteous, ensure that can meet the requirements of measuring practice teaching. Again according to the requirements of the different projects for different experimental practice, like a boxer observation practice, teachers designated location practice fields, each group choose four points and two close to the equilateral triangle, choosing to control the length of the triangle is not too short, some position side length is relatively short, with a thin rod marks on the target, all the more to the accurate measurement site. Otherwise, the results of Angle measurement error is too big.

Engineering surveying practice, between the experimental and theoretical teaching is concentrated in the internship site after two weeks of practice, teachers only at the beginning of the session, decorate practice task, and arrange distribution area, measuring instruments, all subsequent organization by each team practice process. Teachers in the process of practice have not regular inspections, remote supervision and management, students have problems can adopt many ways to answer, greatly exercise the students' practical ability and the level of organization and coordination.

School wide field, topography distribution in accordance with the environmental conditions of the measuring practice. Students in engineering surveying practice in the different area, finally complete the simulation design of measuring area topographic map. The obvious advantages of surveying exercitation field: Multiple times in the same area for the same content of practice teaching, the teacher knew all about teaching environment, timely find problems in students. Such as, for students to choose the location of the root point whether appropriate, results of observation errors, since the data is correct, etc., can know as early as possible, timely guidance to ensure the smooth progress of the comprehensive measuring practice. At the beginning of the internship, the previous topographic map as a template for the reference, to let the students to overcome the fear, 
establish a good map measurement of confidence. In topographic map check and acceptance stage, the longitudinal comparison and contrast of the same topographical map. Relatively fixed internship site, set up to guide teachers to practice the standard grades, easy to objectively assess a student's practice. In the internship students submit summary could express the engineering surveying practice effective and special mention measurement technology capability has improved significantly.

Engineering surveying practice is students to master the measurement, calculation, draw the three basic skills practice, engineering surveying practice include: figure root point set, the structure of the measuring instruments and use of large scale topographic map of the measurement, calculation, drawing, and tracing, and the scene design, etc. For topographic survey practice, it is important to select the appropriate control point position, determination and calculation of three-dimensional coordinates, then according to the control points of houses, roads planar point measurement, calculation and drawing. Let the students in the choice of measurement methods of reconnaissance study, and measuring data calculation and checking and technical requirements, and the ability to implement construction lofting precision.

A person cannot complete engineering surveying, engineering surveying practice but also the task of team work. Seen began to measure is not serious, point-to-point careless, leveling rough around the Angle difference is more than 40 seconds, had to rework the weight measurement; Some students think of quantity and cleverness a job, as a result, wires cannot be closed. Arrange engineering surveying practice in theory teaching, after class time is not the heat is winter, let students experience a wild tough working conditions. They wrote in the summary engineering surveying work really can exercise person's willpower, cultivate people collective idea of teamwork.

\section{Conclusion}

Pay attention to the practice teaching of engineering survey in the process of implementing the teaching reform, fully embodies the student as the standard, the teaching idea of teachers as the leading, exert students' initiative and enthusiasm. The teaching content of this course is mainly based on the actual project to measure experiment practice design, more close to the actual construction site, is advantageous to the students after graduation as soon as possible to adapt to the engineering environment and meet the employment requirements.

After several years of teaching practice, to promote a new teaching pattern of measuring recognized by students, inspire the students interested in engineering surveying course, this in order to ensure the laid the foundation of civil engineering surveying course teaching quality, shorten the distance of the course teaching and the actual engineering, for training applied talents have a positive effect.

\section{Acknowledgement}

In this paper, the research was sponsored by Shanghai municipal education commission key course construction project 2015 - civil engineering surveying (A-0131-16-003026).

\section{References:}

[1] Fuchang Li. Building measurement of construction measurement analysis [J]. Journal of gold card project (economic and law), 2010 (12): 169-170.

[2] Xianli Zhang. Engineering surveying course practice teaching reform to explore [J]. Journal of vocational technology, 2008 (8): 67.

[3] Jing Wei, Hua Lin. About exploration to improve the quality of construction engineering surveying practice teaching [J]. Journal of education and profession, 2007 (21): 87. 
[4] BaoLei Nie, Qingyan Zhang. Project teaching method in the application of the construction engineering surveying courses and practice study $[\mathrm{J}]$. Urban construction theory research (electronic version), 2012 (33): 12-13.

[5] Wusheng Hu. Civil engineering construction survey manual [M]. Beijing: people's traffic press. 2011.

[6] Yan Bao, etc. Integrated into the engineering consciousness of measuring teaching [J]. Journal of civil engineering and construction theory and practice of education reform, 2010, 12 (12): 235-237.

[7] Honggu Wei, Yan Bao etc. Non-professional measurement method of teaching excellence teaching environment [J]. Journal of education teaching BBS, 2013, 2 (8): 1-119-18

[8] Zhengming Wang, Yufang Fan. Understanding of the connotation of the practice education and thinking [J]. Journal of China university teaching, 2014, (2): 68-7 1.

[9] Gang Chen, Liang Hu, etc. Comprehensive university undergraduate course of practical teaching system construction and thinking [J]. Journal of China university teaching, 2013, (11): 76-77 